\title{
A theoretically-based coding system to guide assessment and evaluation of affective learning
}

\author{
Maureen E. Wassef ${ }^{* 1}$, Melissa O'Malley Tuomi ${ }^{2}$, Teresa Finn ${ }^{3}$, Susan Sullivan-Bolyai ${ }^{4}$ \\ ${ }^{1}$ Graduate School of Nursing, University of Massachusetts Worcester, Worcester, MA, United States \\ ${ }^{2}$ Baystate Medical Center, Springfield, MA, United States \\ ${ }^{3}$ Fitchburg State University, Fitchburg, MA, United States \\ ${ }^{4}$ New York University, New York, NY, United States
}

Received: July 23, 2015

DOI: $10.5430 /$ jnep.v6n1p45
Accepted: September 16, $2015 \quad$ Online Published: October 14, 2015

URL: http://dx.doi.org/10.5430/jnep.v6n1p45

\begin{abstract}
Objective: The preparation of reflective practitioners is crucial with the ever changing dynamics of the healthcare environment. Reflection involves the personal collection of information with subsequent contemplation and deliberation. This reflective process serves as the basis for gaining understandings, attaching meaning and guiding future actions. A challenge for nursing faculty is to implement new and innovative methods to assess and evaluate both reflection and affective learning. The purpose of this study is two-fold; to develop a theory-based coding system to assess affective learning, and to evaluate the feasibility and applicability of this coding system in reading and responding to students' reflective clinical journals.

Methods: The coding system is based on an alignment of the affective domain taxonomy and Mezirow's theory of transformative learning. A research team developed this system, and then utilizing predetermined coding guidelines, scored clinical journal entries written by graduate entry pathway students. Inter-rater reliability and qualitative data in the form of faculty anecdotal comments supported on-going revisions to the coding system.

Results: In the early stages of the coding, the IRR averaged 0.5 with the last set ranging from $0.75-1.00$. Team meeting and the use of the research team's anecdotal logs served to address inconsistencies in the process.

Conclusions: The results of this study support the feasibility to both establish a consistent theoretical foundation to guide student assessment and evaluation of affective learning. Identification of student exemplars was also created to orient new faculty concerning the stages of reflection. The results of this study also support the course design process in terms of alignment of student learning objectives, instructional methods and evaluation plans.
\end{abstract}

Key Words: Reflection, Affective domain, Course design

\section{INTRODUCTION}

To prepare nurses for today's healthcare settings, faculty must design transformational experiences that help students form their own professional identity. ${ }^{[1]}$ Once nurse educators embrace this vision, they face the dilemma of how to redesign their pedagogical approaches and evaluate their suc- cess in ultimately preparing students to play integral roles in the current healthcare environment. Reflection is often viewed as a vehicle in which to assist students in the process of forming their professional identifies. It involves the gathering of information with subsequent thought and consideration. This reflection process will serve as the foundation

\footnotetext{
* Correspondence: Maureen E. Wassef; Email: maureen.wassef@umassmed.edu; Address: Graduate School of Nursing, University of Massachusetts Worcester, Worcester, MA, United States.
} 
for gaining understandings, attaching meaning and guiding future actions.

Mezirow's Transformational learning theory ${ }^{[2]}$ is ideal for guiding nurse educators. Transformational learning is based on contextual theories of learning, which conceptualize experiences as events whose meaning is interpreted in relation to one's whole life. It is the focus on meanings and the social conditions that influence the ways in which adult students identify significance of their experience that is missing from the traditional learning. Within the curricular process, the student's personal perceptions and emotional responses to these experiences are typically measured through outcomes in the affective domain. These affective outcomes are observable behaviors and those that reflect inner feelings about a particular concept based on a level of competency. ${ }^{[3]}$ Therefore the purpose of this study is to develop a coding system based on Mezirow's transformational learning theory to provide a consistent approach for faculty to assess student affective learning. This assessment would then provide a foundation to guide faculty in the design of future relevant transformational experiences and in the evaluation of student outcomes.

\subsection{Theoretical framework}

Mezirow suggests that adult learners develop frames of reference as paradigms for viewing the world through prior learning, life experiences and instinctual responses. His theory of transformational learning specifically applies to adults since they have acquired a coherent body of experiences, associations, concepts, values, feelings, conditioned responses and frames of reference that define their life world. It is further suggested that these frames of reference may transform into new thinking when an adult is exposed to reflection in educational environments. It is proposed that the process of transformative learning is initiated by the occurrence of a disorienting dilemma. Typically this disorienting dilemma occurs when an individual encounters a situation where previous assumptions are questioned and subsequently a transformation of perspectives takes place.

Mezirow identifies a series of phases that is initiated by the realization of this disorienting dilemma and the resultant incorporation of a behavior change into their life based on this new perspective. Within this process, the individual journeys through the arduous phases of self-examination, including the assessment of previous assumptions and the conscious planning of strategies to act on this new perspective. The central tenet of Mezirow's theory is for individuals to fully understand the meaning of experiences as grounds for their decisions and actions. Reflective learning is fostered through strategies that enable students to bracket prior judgment, attempt to hold biases in abeyance, and through a critical review of the evidence and arguments, make a determination about the justifiability of the expressed ideas whose meaning is contested. ${ }^{[4]}$

This process of critical reflection, whereby the individual examines their thoughts and feelings in regards to this disorienting dilemma, is an ideal vehicle for transformative learning to occur. In the educational environment, it is the affective learning domain that is intricately tied to the reflective process. ${ }^{[5]}$ In his review and analysis of the evolving theory of transformative leaning, Kitchenham ${ }^{[6]}$ highlights Mezirow's emphasis of the affective component's influence to the overall process. Specifically, he notes that in the evolution of his theory over the years, Mezirow, acknowledges the importance of the affective, emotional and social aspects of transformative learning.

\subsection{Learning domains}

Learning domains include the three concepts of knowledge, skills and attitudes which are formally identified as cognitive, psychomotor and affective. These domains further provide a framework to guide educational experiences. The first learning domain was created under the leadership of Dr. Benjamin Bloom, an educational psychologist. ${ }^{[7]}$ The purpose of the first so-called "Bloom's Taxonomy" was to promote higher forms of thinking in education, such as analyzing and evaluating, rather than just remembering facts. With a strong focus on knowledge development, the cognitive domain was the first taxonomy to be created since it addressed mental processes which were viewed as the most the most traditional form of acquiring knowledge. This taxonomy for the cognitive domain was subsequently updated and slightly revised in the late 1990's to reflect a more active form of thinking. ${ }^{[8]}$ This taxonomy includes 6 different categories beginning with the simplest form of cognitive learning which involves recalling or remembering data and can evolve to the highest level of creating new knowledge. Traditional testing such as exams, essays and papers are the most common forms of evaluating the accomplishment of these categories.

A second domain that was created focused on psychomotor development which examines growth of skills and procedures. Categories listed from the simplest to the most complex address issues of speed and precision of execution. ${ }^{[3]}$ Simulation scenarios and the clinical practicum are frequently utilized venues to evaluate students within this domain. The affective domain assesses and evaluates a growth in feelings or changes in attitudes. The affective domain specifically addresses the manner in which we deal with things emotionally such as values or motivations. ${ }^{[9]}$ The major categories of the affective domain also start out with the simplest behavior and progress to the more complex. The 
first level begins with a more passive awareness, acknowledgment and respect of differences in individual perceptions. These levels progress as the individual becomes more active in participating in critical discourse and places values on certain behaviors (see Table 1). The ultimate goal is for the individual to organize values into priorities by contrasting differences, resolving conflicts and creating their own unique value system. Although learning activities that involve case studies and clinical decision making have all been utilized to enhance the development of the affective domain, it the use of reflective writing that has proved to be most frequently utilized in a variety of healthcare professions. ${ }^{[10,11]}$

Table 1. Affective domain of knowledge

\begin{tabular}{ll}
\hline Levels of Learning & Definition \\
\hline Receiving & The lowest level; the learner is passive and is viewed as listening attentively. \\
Responding & $\begin{array}{l}\text { The learner is not only listening attentively, but also begins to respond to the new information. } \\
\text { In addition to listening and responding to new information, the learner begins to examines the new } \\
\text { knowledge and how it impacts their personal value system. } \\
\text { Valuing }\end{array}$ \\
The learner undergoes a process of conflict resolution between their personal value system and the new \\
knowledge. \\
Internalization
\end{tabular}

\subsection{Reflection and student learning}

An individual's ability to reflect and fully experience transformational learning may vary as the person enters a new profession, experiencing a variety of new concepts, ideas and values. Within the nursing curriculum reflective journaling has been used as a teaching strategy for students to process the meaning of their clinical experiences. Reflective journaling is a widely accepted strategy for guiding students to examine such values as caring, empathy, and professional behaviors within the context of a specific setting/environment. Essentially for transformative learning to take place, there are two important precursor steps which include the disorienting dilemma or event and a critical assessment of assumptions. ${ }^{[12]}$ Both of these steps are frequently, if not always experienced by nursing students as they enter the clinical environment. From issues of end of life care to universal access to healthcare, the students must be given an outlet to integrate their thoughts and feelings within the scope of professional practice.

Reflection and student journaling have been used to stimulate the thinking of students, particularly adult learners, on issues appealing to their emotions. ${ }^{[2]}$ The reflective process in journaling allows nursing students to first describe and then analyze clinical experiences with the ultimate goal of using this knowledge to identify their own future actions. Reflective journaling is also used to evaluate students' exploration and acceptance of personal values, attitudes, and beliefs. Whereas faculty can evaluate students' cognitive knowledge of values, attitudes, and beliefs through traditional test questions, a student's acceptance of these concepts can only be evaluated through observation of practice behaviors and reflective journaling. ${ }^{[13]}$ The overall success of this teaching

Published by Sciedu Press and learning strategy depends on clear guidelines, objectives, and expectations for the reflective journal. Faculty members must not only clarify these expectations for students, but also provide consistent and specific feedback. ${ }^{[11]}$

Epp conducted a review of the literature to assess the evidence for the value of reflection as a teaching strategy in nursing education. In addition to identifying evidence that instructors struggle to incorporate reflective processes into education, the research did provide the support and rationale for engaging students in the reflective process. ${ }^{[14]}$ Chirema investigated the use of reflective journals in the promotion of reflection and learning in nursing students. ${ }^{[15]}$ Within her study, she conducted interviews of both students, teachers and preceptors. Students in particular identified the use of reflective journal writing to create new ideas which link theory and practice as well as enhancing their awareness of the learning they have achieved along with its application. The link between reflective journaling and experiential learning is also addressed in the literature. Experiential learning or learning by doing and the application of theory into practice are significant components of nursing education. As such, the use of reflective journaling can potentially foster the actual learning process. Fowler conducted an analysis of the concept of experiential learning and concluded that it is the result of reflecting on one's experiences. ${ }^{[16]}$ Journaling has been used in both medical education and nursing clinical experiences to foster student reflection. ${ }^{[10,17,18]}$ Similarly, student-reaction essays were also used as a method to guide medical students in exploring and clarifying misconceptions, values, and attitudes concerning aging and palliative care. ${ }^{[19]}$ These studies and others have demonstrated the utility of using Mezirow's theory of transformational learning, ${ }^{[20,21]}$ 
and the affective domain ${ }^{[22,23]}$ to guide reflective journaling. In particular, Wong and colleagues ${ }^{[21]}$ acknowledged the lack of empirical evidence related to assessment of reflective learning.

\subsection{Implications for nursing education}

It is proposed that the alignment of the five levels of the affective domain and reflective stages can also provide guidance to the nurse educator in the process of clinical course design. Within the course design process, after identifying the title, purpose and description, the crafting of student objectives, instructional strategies and subsequent evaluation methods are needed. The affective domain is an integral part of creating student goals and expectations which guides the educator to identify appropriate learner outcomes/competencies, and identify key clinical experiences. Course objectives need to be first identified based on the focus of the clinical experience and expected level of the student. If the students will have a clinical experience involving hospice care, the faculty may have them focus in their reflective journals on themes of dignity and end of life care. Based on a senior level clinical group, the fourth level of organization may be selected where in their clinical journals the student identifies these concepts in relation to the specific clinical situation. It would be expected that these student will be beginning to organize values into priorities by contrasting different values based on these themes. The next challenge is how to evaluate the successful achievement of these student objectives (see Figure 1).

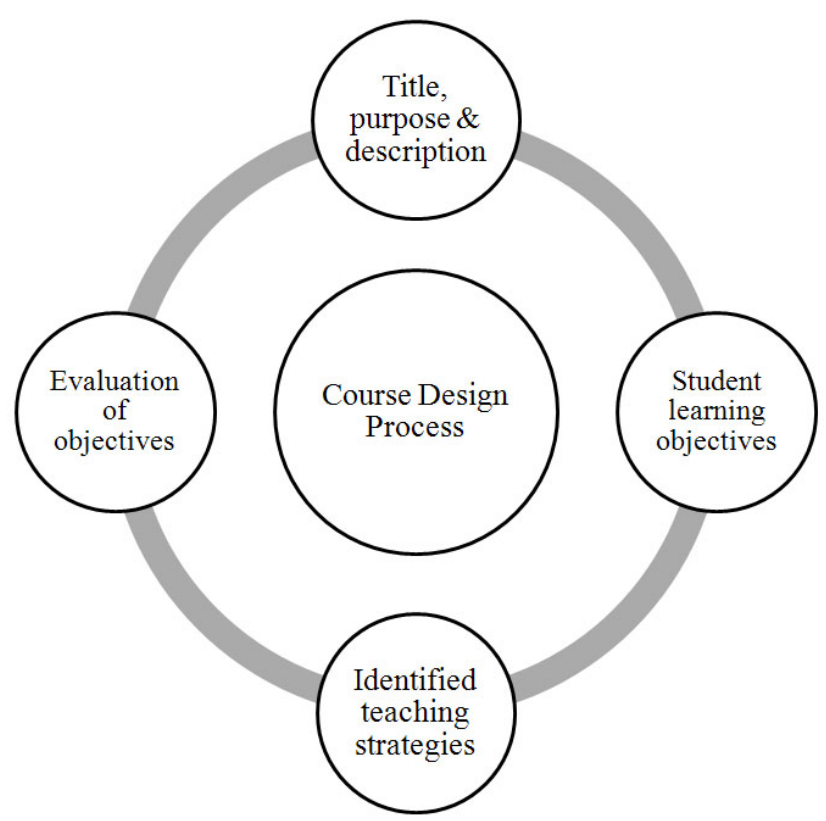

Figure 1. Course design process

Application of the principles of transformational learning and Mezirow's reflective principles can provide the theoreti48 cal basis for the evaluation of these outcomes. This can be accomplished through the strategy of reflective journaling where the faculty can evaluate the successful achievement of the identified course affective goal statements. There have been numerous difficulties cited in regards to previous attempts to successfully assess student reflective abilities. Key omissions in prior work in assessing reflective practices include a lack of a consistent definition and underlying principles grounding this process. It is then recommended that after a definition and guiding principles are selected, criteria to interpret reflection assessment should be identified. ${ }^{[24]}$

One approach documented in the literature is developing reflective stages based on the ranking of five levels or categories. These stages range from unreflective to critical reflection. Bouner ${ }^{[25]}$ then suggests that based on the theoretical principles underlying the process, observable behaviors are identified which exemplify each category and may provide a more objective manner in which to assess reflection. Their focus was to establish an approach to evaluate the level of student reflective abilities and they concluded that Mezirow's work served as an effective framework for identifying levels of reflections. They recommended as a next step, the development of a method for evaluating the extent and quality of the reflection and its influence on the overall curriculum.

\section{METHOD}

The purpose of this study is two-fold; to develop a theorybased coding system to assess affective learning, and to evaluate the feasibility of applying this coding system in reading and responding to students' reflective clinical journals. In developing the first draft of the coding system template, a table was created by aligning the five levels of the affective domain with a theoretical category of reflection guided by Mezirow's theory of transformative learning (see Table 2). One of the more recent studies involving the use of a reflection rubric to identify reflection in student nurses, focused on three basic levels of the reflective process: nonreflection, reflection and critical reflection. ${ }^{[26]}$ In our current study, the decision was made to create five levels to further identify the nuances of reflection in the clinical setting as well as a way to better align these levels with affective outcomes.

Our next step in the procedure was to develop criteria focusing on each category with specific references to a clinical experience. For example, the first level of the affective domain refers to responding which is defined as a passive awareness. This was aligned with that of a non-reflector and the assessment criteria focused on a student clinical journal which consisted of pure descriptive writing. Each level was then developed in regards to affective domain, corresponding level of reflection and defining criteria. 
Table 2. Alignment of affective domain \& reflective stages

\begin{tabular}{ll}
\hline Affective Domain Levels & Reflective Stages \\
\hline $\begin{array}{l}\text { Receiving Phenomena: passive awareness } \\
\begin{array}{l}\text { Responding to Phenomena: beginning to exhibit active participation on the } \\
\text { part of the learners. Attends and reacts to particular phenomenon. }\end{array}\end{array}$ & $\begin{array}{l}\text { Non-reflector: No evidence of reflection } \\
\text { Reflector I: Demonstrates an awareness of a concept and } \\
\text { introduces it in writings with limited reflection. }\end{array}$ \\
$\begin{array}{l}\text { Valuing: The worth or value a person attaches to a particular object, } \\
\text { phenomenon, or behavior. This ranges from simple acceptance to the more }\end{array}$ & $\begin{array}{l}\text { Reflector II: Demonstrates understanding of a concept and } \\
\text { applies it to a specific scenario }\end{array}$ \\
$\begin{array}{l}\text { Oomplex state of commitment. } \\
\begin{array}{l}\text { Organization: Organizes values into priorities by contrasting different } \\
\text { system. The emphasis is on comparing, relating, and synthesizing values. }\end{array}\end{array}$ & $\begin{array}{l}\text { Critical Reflector I: Demonstrates understanding of a } \\
\text { concept, applies it to a specific scenario, and further explores } \\
\text { how this understanding has impacted his/her own behavior }\end{array}$ \\
$\begin{array}{l}\text { behavior. The behavior is pervasive, consistent, predictable, and most } \\
\text { importantly, characteristic of the learner. Instructional objectives are } \\
\text { concerned with the student’s general patterns of adjustment (personal, social, } \\
\text { emotional). }\end{array}$ & $\begin{array}{l}\text { Critical Reflector II: Demonstrates consistent understanding } \\
\text { of a concept, applies it to a specific scenario and further } \\
\text { explores how this understanding has impacted his/her } \\
\text { current and future behavior }\end{array}$ \\
\hline
\end{tabular}

\subsection{Sample and setting}

Once this initial coding system was devised, the second part of the study was launched. The next step was to evaluate the feasibility and applicability of this coding system in reading and responding to students' reflective clinical journals. The study analyzed existing data that was collected routinely as part of normal teaching practices for students enrolled in the clinical course. The potential sample included 27 Graduate Entry Pathway nursing students enrolled in a clinical course focusing on acute and chronic illness. Students in the Graduate Entry Pathway Program possess a minimum of a bachelor's degree in another field and will graduate with a graduate degree in nursing. Within this program students complete their core pre-licensure nursing classes within one year and this includes a total of three clinical semesters. This particular clinical course occurred within their second semester of clinical practice. The weekly journals focused on core themes and values based on the course objectives. These included core professional practice behaviors of patient advocacy, inter-professional communication, legal/ethical implications of care, and cultural competence. The student assignment consisted of weekly journal submissions where the students were asked to discuss and reflect on one of the core professional practice behaviors that pertained to their weekly clinical assignment. The journal assignment was a component of their clinical practicum which was graded on a pass/fail basis.

The research study was reviewed by the institution's IRB and met criteria for exempt status. The authors were not faculty members associated with the course and met with the students on their last class day to introduce the study purpose. This time was chosen to avoid biasing how the students wrote in their journals due to study participation. The students were given a fact sheet about the study and told that if they did not want their journals to be analyzed in the study, they could inform the course coordinator and their journals would be removed. To ensure participants' confidentiality and anonymity, no individual demographic information was collected. Each student and her or his associated data were assigned an identification number by the class instructor who was not involved in the study. To reassure students that participation in the study would not affect their course grade, their journals were not read until after the course had formally ended and their final grades were submitted to the registrar.

\subsection{Procedure}

The research team consisted of doctoral prepared graduate nursing faculty and graduate nursing student research interns. The research team coding the journals was comprised of four members, who independently analyzed each journal. All team members attended an orientation session on the coding system and the procedure for analyzing journal content. ${ }^{[21]}$ The identification of these principles was essential to ensure structure and consistency among the team members. The coding principles (see Table 3) included the following: repeated points or arguments are coded only once; if a coder perceives that a student is between coding stages within a paragraph, the coding is based on the lower stage of the coding system; coding is only valid with evidence or substantiation; coding must be supported by textual data and quotes from the literature to illustrate or substantiate a student's own experience are amenable to coding, but quotes that merely demonstrate textbook knowledge are not coded; concepts in the student journals that pertain to personal issues are excluded from coding and finally coders must maintain a personal log to validate their decision making. 
Table 3. Coding guidelines

- $\quad$ Repeated points or arguments are coded only once.

- If a coder perceives that a student is between coding stages within a paragraph, the coding is based on the lower stage of the coding system.

- $\quad$ Coding is only valid with evidence or substantiation.

- $\quad$ Coding must be supported by textual data. Interpretive speculation is not acceptable.

- $\quad$ Quotes from the literature to illustrate or substantiate a student's own experience are amenable to coding, but quotes that merely demonstrate textbook knowledge are not coded.

- $\quad$ Concepts in the student journals that pertain to personal issues are excluded from coding.

- $\quad$ Coders must maintain a personal log to validate their decision making.

Team members reviewed and coded each paragraph of the student journals for evidence of key course concepts. An electronic spreadsheet was provided to all team members to manage their data. As mentioned, each member of the team kept a log during the study and documented any issues or difficulties they experienced following these principles. This log also maintained a theoretical audit trail of each team member's process of coding the journals. Credibility of the data was maintained since the data (student journals) were written by the student participants without prior knowledge of the study.

A sample of 25 students agreed to have their journals analyzed for the study. It was decided to choose three journal entries for each student. During the 6 week clinical rotation, it was proposed that one journal entry was to be analyzed from the beginning, middle and end of the experience (weeks 1,3 and 5). This resulted in 75 journal entries for analysis. Three journals were used as a "pilot" to initially introduce the process to the team. These were not included in the final analyses. The team identified two benchmark goals for the analyses of all of the journals. The first is that the target IRR would be $>0.75$ and second, that the team log books indicated the issue of reaching saturation or information redundancy in regards to the crafting of the coding system criteria. Each team member electronically received the weekly journals, independently reviewed the journals for content analysis, scored the journal based on a numerical scale of 1-5 (1: non-reflector and 5: critical reflector II) and provided ongoing feedback on refining the coding scheme via their logs.

After each faculty coder had analyzed at least five journals, the team submitted their numerical scores and personal logs. An inter-rater reliability (IRR) among coders was calculated as the number of agreements/(number of agreements + disagreements). Within this study the calculation of the interrater reliability was conducted as a measure to support the consistency and predictability of this coding system. Before analyzing the next group of journals, the team provided feed- back on the process and discussed any need for revising the coding system.

\section{RESULTS}

In the early stages of the coding, IRR between faculty averaged 0.5 with the last set of 10 journals ranging from 0.75 1.00. Discrepancies among the coding primarily revolved around differentiating between two levels of the coding system. For example, one difficulty evolved over differentiating between a stage 3 and a stage 4 when analyzing the journal content. The assessment criteria for these two stages were refined based on the faculty input and discussion. Additional issues in differentiating between stages were resolved through a similar process focusing on making additional revisions to the assessment criteria, specifically to further differentiate between the stages. Team log books indicated the achievement of saturation in relation to evidence supporting the creation of the assessment criteria for the coding system.

Within this study we were able to devise a coding system based on theoretical principles with the goal of assessing and ultimately evaluating the affective domain of students in the clinical environment through the use of reflective journaling. IRR between the research team coding student journals initially averaged 0.50 . With the use of research team logs and anecdotal comments, the IRR was improved with a range of $0.75-1.00$. The calculation of the inter-rater reliability was conducted to ideally ensure the consistency of this coding system when used with a variety of student and faculty. In addition, since student demographics were not collected, external validity is limited in regards to cultural variations.

These IRR findings are similar to those reported by Wong and Colleagues who used a two level coding system. Their IRR were reported as 0.88 on a first level of coding analyzing paragraphs of text and a range of 0.5-0.75 when identifying categories of reflection. Acceptable levels of IRR can differ through-out the literature, but a general rule of thumb is that 0.60 is deemed to be minimally acceptable with the benchmark goal being 0.75 or higher. ${ }^{[27]}$ 
As important and crucial as the calculated IRR was to the study, the anecdotal comments from the research team's logs after their analyses of the journals were the most instrumental in identifying three key areas that needed to be addressed The issue of "vague" terminology was a concern for many team members. For example, the original assessment criteria for the stage 2, receiving/reflector I discussed the student's "global awareness of concepts". The members felt that a more concrete, objective set of criteria was needed so that it could be universally understood. Another common topic was over how to code a journal that was inconsistent (for example, the entire journal was descriptive until the last few sentences revealing an "aha" moment). A more persistent theme among the logs that needed clarification and revision was the issue of differentiating between two consecutive categories. It was through these discussion that the final version of the coding system was derived (see Table 4). One anecdotal comment that was prevalent among the team members was the need for clear communication to the students in regards to the purpose of the journal assignment. A further discussion ensued around the need for assignment guidelines and the communication of faculty expectations to the students. Past student statements on course evaluations echoed this sentiment. Essentially, the students enjoyed the opportunity for self-reflection, but did not always feel they clearly understood the expectations of their clinical instructors regarding the assignment.

Table 4. Coding system

\begin{tabular}{|c|c|c|c|}
\hline 1) & Receiving/Non-reflector & Passive awareness of new concept & No evidence of reflection: descriptive writing \\
\hline 2) & Responding/Reflector I & $\begin{array}{l}\text { Begins to demonstrate an active discussion } \\
\text { pertaining to a concept }\end{array}$ & $\begin{array}{l}\text { Demonstrates an awareness of a concept and } \\
\text { introduces it in writings with limited reflection. } \\
\text { (Provides just a glimpse of reflection on the meaning } \\
\text { of the concept; leaves the reader thinking, "What } \\
\text { about it?") }\end{array}$ \\
\hline 3) & Valuing/Reflector II & $\begin{array}{l}\text { Relates concepts to a specific } \\
\text { context/clinical situation }\end{array}$ & $\begin{array}{l}\text { Demonstrates understanding of a concept and applies } \\
\text { it to a clinical scenario }\end{array}$ \\
\hline 4) & $\begin{array}{l}\text { Organizing/Critical } \\
\text { Reflector I }\end{array}$ & $\begin{array}{l}\text { Discusses concept in relation to clinical } \\
\text { situations and own behaviors }\end{array}$ & $\begin{array}{l}\text { Demonstrates understanding of a concept, applies it } \\
\text { to a clinical scenario, and further explores how this } \\
\text { understanding has impacted his/her own behavior }\end{array}$ \\
\hline 5) & $\begin{array}{l}\text { Internalizing/Critical } \\
\text { Reflector II }\end{array}$ & $\begin{array}{l}\text { Consistently (over the course of a } \\
\text { semester) discusses a concept in relation to } \\
\text { specific situations and in regard to its } \\
\text { effect on their professional behaviors }\end{array}$ & $\begin{array}{l}\text { Demonstrates consistent understanding of a concept, } \\
\text { applies it to a clinical scenario and further explores } \\
\text { how this understanding has impacted his/her current } \\
\text { and future behavior }\end{array}$ \\
\hline
\end{tabular}

\section{Discussion}

The results of this present study do support the need to both establish a consistent theoretical foundation to guide student assessments and maintain communication among faculty regarding the clarification and interpretation of the assessment criteria. In an attempt to further streamline this process, student journal entries were then used to guide the development of fictitious exemplars of the first four stages (see Table 5). The purpose of this was to use these as guides in orienting future faculty to the coding system. For example, the category of "receiving/non-reflector", i.e., no evidence of reflection, was exemplified by the excerpt describing a student's daily routine: "we spent most of the day working with an elderly woman who was diagnosed with Parkinson's disease; she ambulated with the use of a cane and required physical therapy session each day." Faculty responses may include asking the student to further discuss their interactions with the woman regarding individualized discharge planning. The next category of "responding/reflector" includes a student who begins to show awareness of some classroom concepts, but stops before exploring its meaning in the clinical scenario. This category was illustrated by the following excerpt: " $m y$ patient was incontinent for most of my shift; she felt very embarrassed and uncomfortable having others clean her up. This reminded me of our class discussion that discussed the concept of 'dignity and the older adult'." In this case, the faculty will naturally ask the student to further reflect on how specifically the concept of dignity applies to their interactions with this particular patient.

The student who exhibits evidence of valuing or being a reflector II now begins to demonstrate in writing not only the understanding of a concept, but also applying to their specific clinical scenario. "I attended a group mobility class and I thought it would be very low level, but each of the patients cheered each other on. The result of all of the interactions was that each one was pushing themselves harder. One gen- 
tleman who had cerebral palsy was having some difficulty and I wanted to go over and help him. I felt very inadequate because I could not go over and help him with his exercises." In this case, the faculty may respond to the student in an attempt to foster them to the next level. Here they may ask the student to reflect on how they may or may not alter their behavior in similar situations in the future.

Table 5. Stages \& exemplars

\begin{tabular}{|c|c|}
\hline Affective Domain Level/Reflection Stage & Exemplar \\
\hline Receiving/Non-reflector & $\begin{array}{l}\text { "We spent most of the day working with an elderly woman who was diagnosed with } \\
\text { Parkinson's disease; she ambulated with the use of a cane and required physical } \\
\text { therapy session each day." }\end{array}$ \\
\hline Responding/Reflector I & $\begin{array}{l}\text { "My patient was incontinent for most of my shift; she felt very embarrassed and } \\
\text { uncomfortable having others clean her up. This reminded me of our class discussion } \\
\text { that discussed the concept of 'dignity and the older adult'." }\end{array}$ \\
\hline Valuing/Reflector II & $\begin{array}{l}\text { "I attended a group mobility class and I thought it would be very low level, but each } \\
\text { of the patients cheered each other on. The result of all of the interactions was that } \\
\text { each one was pushing themselves harder. One gentleman who had cerebral palsy } \\
\text { was having some difficulty and I wanted to go over and help him. I felt very } \\
\text { inadequate because I could not go over and help him with his exercises." }\end{array}$ \\
\hline Organizing/Critical Reflector I & $\begin{array}{l}\text { "I did not know what to expect on my first day at the rehab facility. Rather than } \\
\text { caring for passive, deflated bodies, I was interacting with vibrant, motivated } \\
\text { individuals. I truly began to appreciate the benefit and worth of the facility. My } \\
\text { patient was elderly, but was always treated with respect. As a result she seemed } \\
\text { happier than other elderly patients that I have cared for. I was so excited about my } \\
\text { experience that I went home to learn more about the principles of rehab. It is my goal } \\
\text { to be much more interactive during my next clinical day." }\end{array}$ \\
\hline
\end{tabular}

The organization/critical reflector I not only demonstrate the awareness of the concept, applies it to their clinical situation, but also explores how this has impacted their behavior. "I did not know what to expect on my first day at the rehab facility. Rather than caring for passive, deflated bodies, I was interacting with vibrant, motivated individuals. I truly began to appreciate the benefit and worth of the facility. My patient was elderly, but was always treated with respect. As a result she seemed happier than other elderly patients that I have cared for. I was so excited about my experience that I went home to learn more about the principles of rehab. It is my goal to be much more interactive during my next clinical day." The last stage of internalization/critical reflector II is exhibited consistently over time through the integration of these key concepts, applying them to their clinical situation and evaluating and exploring their behavior for the future.

When considering other strategies in which to guide students through the reflection process, several question arise. Would it help students to become better reflectors by providing them with expected steps on how to proceed? For example, should the students be provided with the actual coding system and be told up front that they are expected to achieve a certain level? How should one work with a student who struggles with their writing skills and may be unable to truly convey their reflective abilities in this manner? The development of this coding system is a first step to address these fundamentally key issues.

Finally, when there is a discussion concerning the issue of evaluation, the issue of grading must then be addressed. The assertion remains that the alignment of the five levels of the affective domain and reflective stages will results in a seamless curricular process that guides the educator to identify appropriate learner outcomes/competencies. The overall intention of the evaluation process is to provide meaningful and theoretically based feedback to the student to guide them in the reflection process. A numerical grade is not provided since the journal and clinical experience is graded as pass/fail. In addition, it was the philosophical decision of our research team members that going forward, the students would receive only anecdotal feedback guided by the coding system and not a number based on the stage. In this way, the team members did not want to put a number value on the student's values and beliefs. Utilizing this coding system, a student's progress within the reflective process is identified based on their alignment between the expected outcome and reflective stage demonstrated by their journal entries. 


\section{Conclusion}

Benner and colleagues' call for a transformation in nursing education remains a landmark document to guide faculty through the changes of the 21 st century. The challenge is now to develop a program of research in nursing education which identifies strategies to foster the development of the nurse of the future. Utilizing a theoretically based coding system to assess affective learning will provide a foundation for developing and evaluating learning outcomes through the process of assessing reflective behaviors in the clinical setting. Continued work and utilization of this coding system is required, but does lay the ground work for developing a body of knowledge within assessment and curricular evaluation in nursing education. Moving forward, one of the more practical issues to address implementation will involve the ease of use for faculty and student and utilizing this coding system in conjunction with a learning management system (LMS). There will continue to be critics of journaling labeling this strategy as a waste of time and a vehicle for busy work. This sentiment was expressed by both students and educators in an article by Coward. ${ }^{[28]}$ Much of this dissatisfaction stems from inconsistencies of how to define reflection and the ultimate purpose of the assignment. Creating theoretically based methods to assess, guide and evaluate students is just one of the first steps to incorporate evidence based teaching strategies into nursing education. Consistent with the vision of Morris \& Faulk, transformative learning in nursing is one way to integrate innovative pedagogies into curriculums and ultimately answer the challenge for reform in nursing education.

\section{ACKNOWLEDGEMENTS}

This project was funded through the Innovation in Medical Education Grant sponsored by the University of Massachusetts Medical School.

\section{CONFLICTS OF INTEREST Disclosure}

The authors declare that there is no conflict of interest.

\section{REFERENCES}

[1] Benner P, Sutphen M, Leonard V, et al. Educating nurses: A call for radical transformation. Stanford, CA: Jossey-Bass. 2010.

[2] Mezirow J. Transformative dimensions of adult learning. San Francisco: Jossey-Bass, Inc. 1991.

[3] Gronlund N, Brookhart S. Writing instructional objectives. Upper Sadle River, NJ: Prentice Hall. 2009.

[4] Clark MC, Wilson A. Context and rationality in Mezirow's theory of transformational learning. Adult Education Quarterly. 1991; 41(2): 75-91. http://dx.doi.org/10.1177/0001848191041002002

[5] Morris A, Faulk D. Transformative learning in nursing. New York: Springer; 2012.

[6] Kitchenham A. The evolution of John Mesirow's Transformative Learning theory. $\mathrm{J}$ of Transformative Education. 2008; 6: 104. http://dx.doi.org/10.1177/1541344608322678

[7] Bloom B. Taxonomy of educational objectives, handbook I: the cognitive domain. New York: David McKay Co., Inc. 1956.

[8] Billings D, Halstead J. Teaching in nursing-a guide for faculty. St. Louis: Elsevier, 2012.

[9] Krathwohl D, Bloom B, Masia B. Taxonomy of educational objectives: Book 2-affective domain. New York: Longman, 1964.

[10] Arnold L, Shue C, Jones D. Implementation of geriatric education into the first and second years of a baccalaureate-MD degree program. J of Med Education. 2002; 77: 933-934. http: //dx.doi.org/10.1097/00001888-200209000-00038

[11] Bradshaw M, Lowenstein A. Innovative teaching strategies in nursing and related health professions. Sudbury, MA: Jones and Bartlett. 2011.

[12] Brock S. Let's spread the word about the wisdom of transformative learning. J Transformative Learning. 2015: 18-21. PMid:25995770

[13] Oermann M, Gaberson K. Evaluation and testing in nursing education. 3rd ed. New York: Springer; 2009.

Published by Sciedu Press
[14] Epp S. The value of reflective journaling in undergraduate nursing education: a literature review. Int J Nursing Studies. 2008, 45: 13791388. PMid:18325522 http://dx.doi.org/10.1016/j.ijnur stu. 2008.01.006

[15] Chirema K. The use of reflective journals in the promotion of reflection and learning in post-registration nursing students. Nurse Education Today. 2007; 27: 192-202. PMid:16815600 http://dx .doi.org/10.1016/j.nedt.2006.04.007

[16] Fowler J. Experiential learning and its facilitation. Nurse Education Today. 2008; 28: 427-433. PMid:17881093 http://dx.doi.org /10.1016/j.nedt.2007.07.007

[17] Twibell R, Hermiz M. Faculty perceptions of critical thinking in student clinical experiences. J of Nursing Education. 2005; 44: 71-79. PMid:15719714

[18] Myrick F. Preceptorship and critical thinking in nursing education. J of Nursing Education. 2002; 41: 54-164.

[19] Rosenbaum M, Lobas J, Ferguson K. Using reflection activities to enhance teaching about end-of-life care. J of Palliative Med. 2005; 8 : 1186-1195. PMid:16351532 http://dx.doi.org/10.1089/jpm .2005 .8 .1186

[20] Jensen SK, Joy C. Exploring a model to evaluate levels of reflection in baccalaureate nursing students' journals. J of Nursing Education. 2005; 44: 139-142. PMid:15787024

[21] Wong F, Kember D, Chung L, et al. Assessing the level of student reflection from reflective journals. J of Advanced Nursing. 1995; 22: 48-57. http://dx.doi.org/10.1046/j.1365-2648.1995 $.22010048 . x$

[22] Plack MM, Driscoll M, Blissett S, et al. A method for assessing reflective journaling. $\mathrm{J}$ of Allied Health. 2005; 34: 199-208 PMid:16529182

[23] Plack MM, Driscoll M, Marquez M, et al. Assessing reflective writing on a pediatric clerkship by using a modified Bloom's taxonomy. Ambulatory Pediatrics. 2007; 7(4): 285-291. PMid:17660099 http://dx.doi.org/10.1016/j.ambp.2007.04.006 
[24] Koole S, Dornan T, Aper L, et al. Factors confounding the assessment of reflection: a critical review. BMC Med Education. 2011; 11. http://dx.doi.org/10.1186/1472-6920-11-104

[25] Bourner T. Assessing reflective learning, Education + Training. 2003; 45: 267-272.

[26] Kleinheksel AJ. Transformative learning through virtual patient simulations: predicting critical student reflections. Clinical Simulation in Nursing. 2014; 10: 301-308. http://dx.doi.org/10.1016/j .ecns. 2014.02.001

[27] Polit D, Beck C. Nursing research. Philadelphia: Lippincott; 2008.

[28] Coward M. Does the use of reflective models restrict critical thinking and therefore learning in nursing education? What have we done? Nurse Education Today. 2011; 31: 883-886. PMid:21333414 http://dx.doi.org/10.1016/j.nedt.2011.01.012 